\title{
Extractive Desulfurization and Denitrogenation from Fuel Oil by A Polyether Amine-based Solvent
}

Shuang Zhu, Hanlin Cheng, Yafen Dai, Jiajun Gao *, and Xingmao Jiang *

\footnotetext{
${ }^{*}$ Corresponding author

E-mail: gaojiajun@wit.edu.cn (J. Gao); jxm@wit.edu.cn (X. Jiang)

Tel: +86 2787194980
} 


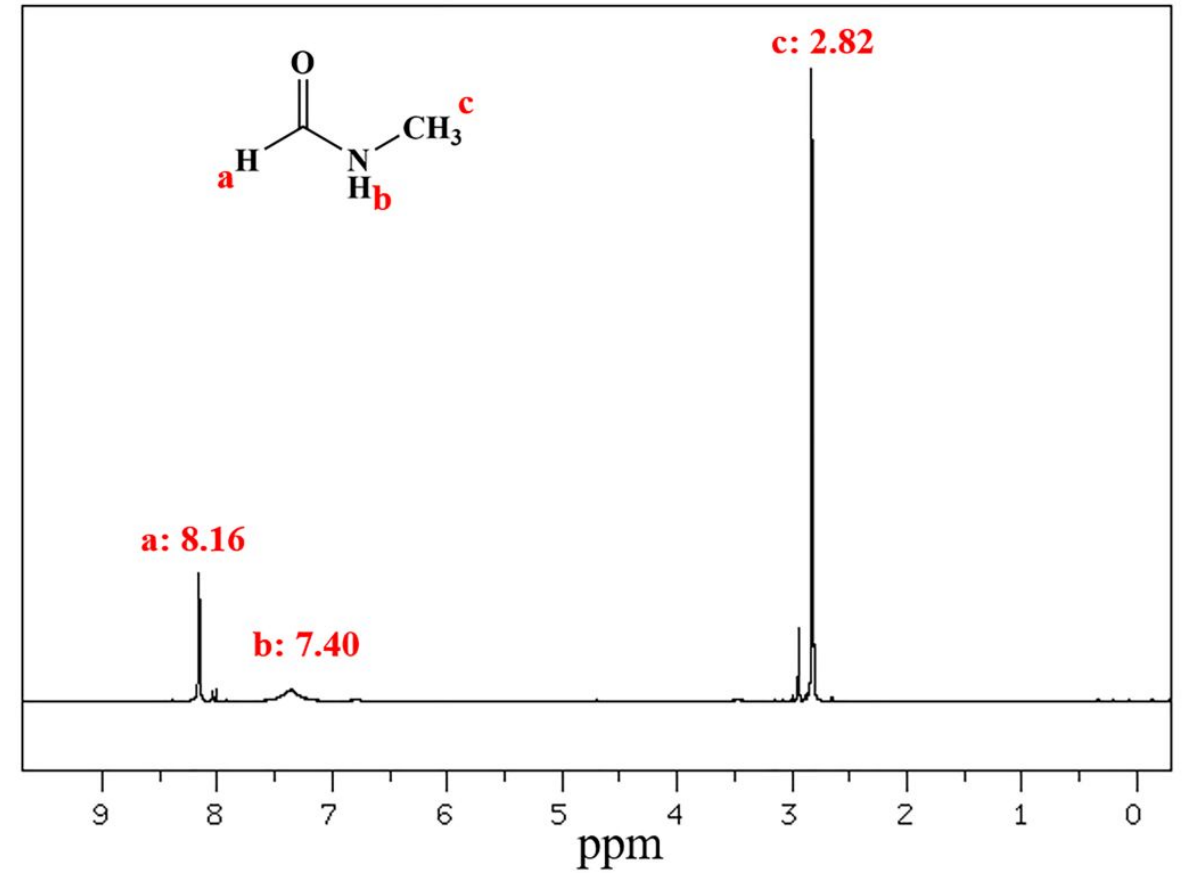

Fig. S1 ${ }^{1} \mathrm{H}-\mathrm{NMR}$ standard spectra of N-methylformamide 


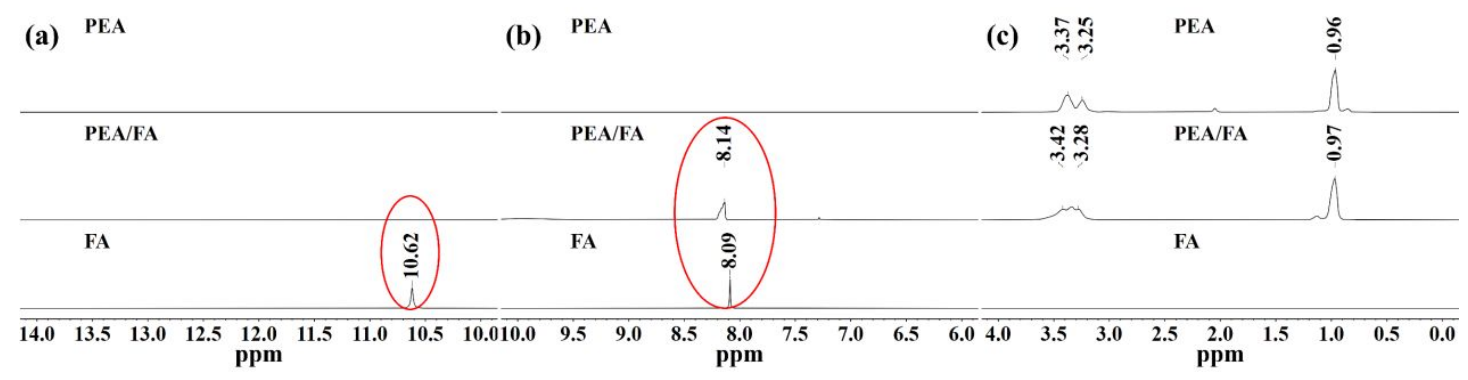

Fig. S2 ${ }^{1} \mathrm{H}-\mathrm{NMR}$ spectra of PEA, FA and PEA/FA complex in $\mathrm{CDCl}_{3}$ solvent 


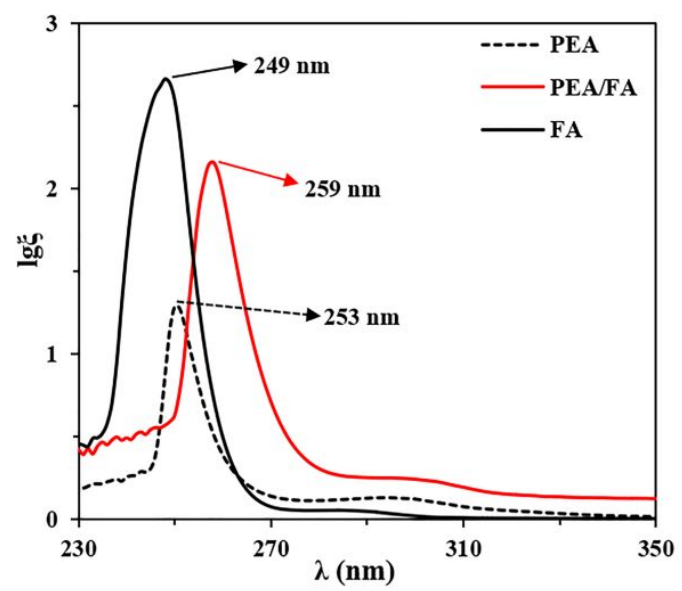

Fig. S3 UV-vis spectra of PEA, FA and PEA/FA complex 


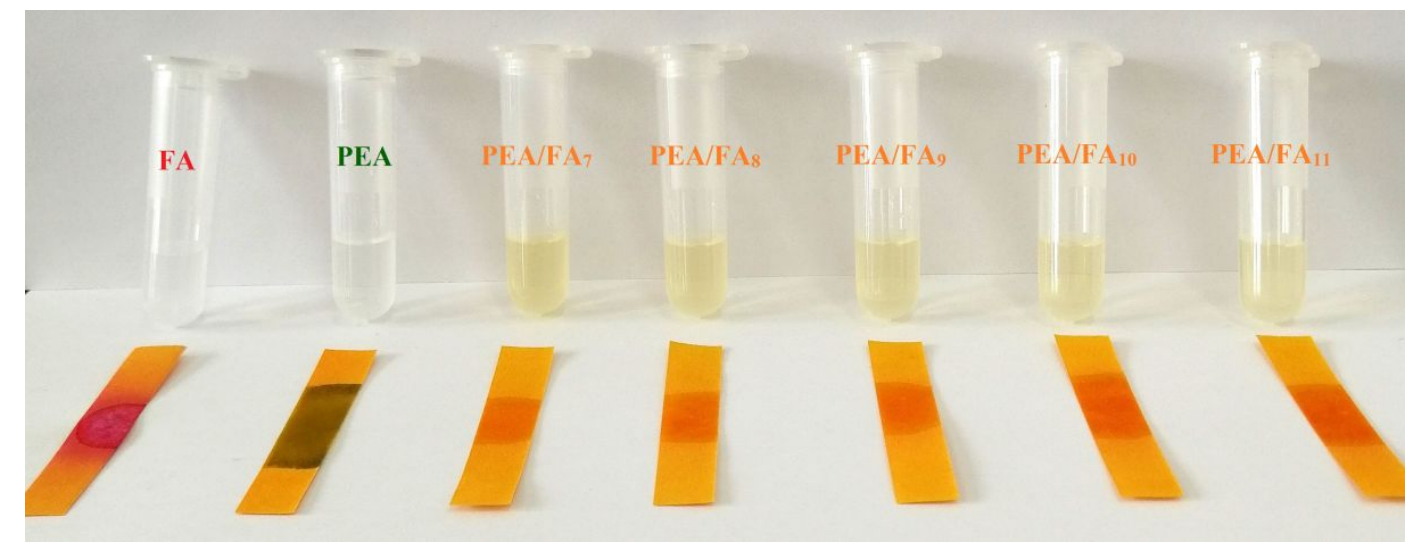

Fig. S4 Influence of molar ratio of PEA/FA complex on apparent acidity 

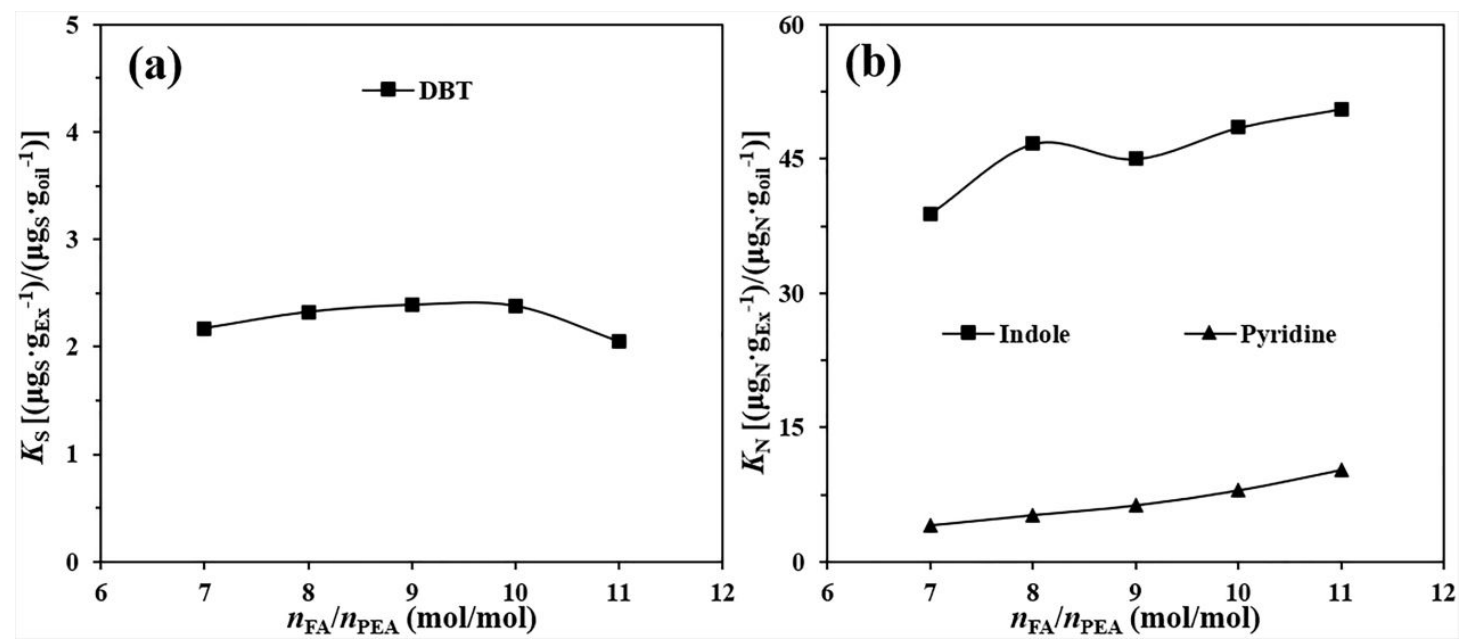

Fig. S5 Influence of molar ratio of PEA/FA complex on $K_{\mathrm{S}}$ and $K_{\mathrm{N}}$ 
(a) Sole DBT

$5: 3$

(b) $\frac{3 y z}{x y}$

Sole DBT

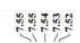
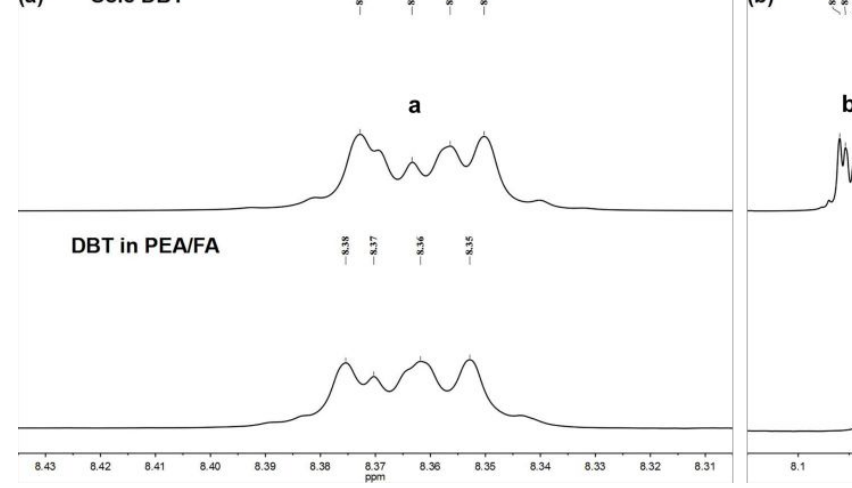

b

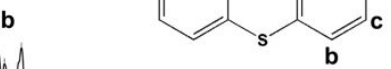

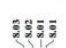

DBT in PEA/FA
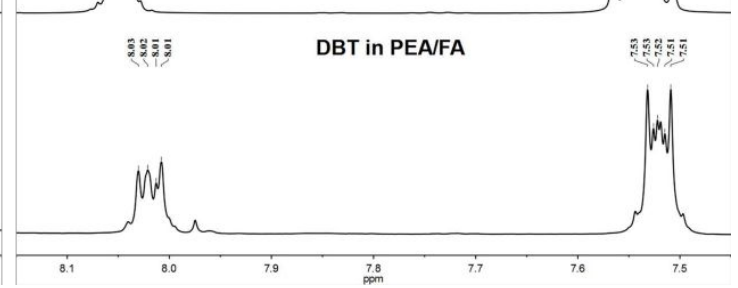

Fig. S6 ${ }^{1} \mathrm{H}-\mathrm{NMR}$ spectra of DBT and its complex with PEA/FA 


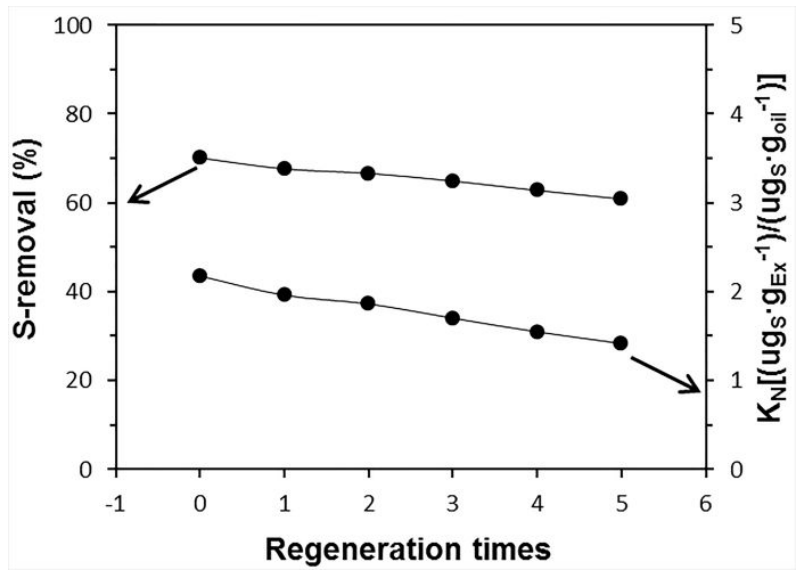

Fig. S7 Regeneration of PEA/FA complex $\left(n_{\mathrm{PEA}} / n_{\mathrm{FA}}=1 / 10 ; m_{\mathrm{Ex}} / m_{\mathrm{oil}}=1 / 1 ; t=15\right.$ $\min ; T=30{ }^{\circ} \mathrm{C}$ ) 
Table S1 Solubility and residual N-content of PEA/FA complex in $25 \mathrm{wt} \%$ toluene containing oil

\begin{tabular}{ccc}
\hline$n_{\mathrm{FA}} / n_{\mathrm{PEA}}$ & Residual N-content $\left(\mathrm{mg}_{\mathrm{N}} / \mathrm{L}\right)$ & Solubility $(\mathrm{g} / \mathrm{L})^{\mathrm{a}}$ \\
\hline 7 & 29.4 & 2.438 \\
8 & 26.2 & 2.217 \\
9 & 16.0 & 1.381 \\
10 & 14.6 & 1.281 \\
11 & 10.3 & 0.918 \\
\hline
\end{tabular}

Note: a. solubility of PEA/FA was calculated by the residual N-content. 